\title{
Genetical control of amylose content in a diallel set of rice crosses
}

\author{
H. S. POONI*, ISH KUMAR† \& G. S. KHUSH \\ School of Biological Sciences, University of Birmingham, Edgbaston, Birmingham B15 2TT, U.K., tProAgro, Hyderabad, \\ India and $\ddagger$ Department of Plant Breeding, IRRI, Philippines
}

\begin{abstract}
Models proposed by Gale and Pooni, Kumar and Khush are applied to study the inheritance of amylose content in a diallel set of crosses produced from seven elite inbred lines of indica rice representing all the major rice consuming regions of the world. In theory, the standard (Hayman's and Griffing's) analyses of diallel tables and the $W r / V r$ relationship are found to apply even though the trait under investigation is expressed in a triploid state. It is further revealed that reciprocal effects can only be detected unambiguously in the $F_{2}$ diallel and the additive and non-additive effects cannot be separated in the $\mathrm{B}_{1}$ and $\mathrm{B}_{2}$ diallels when they are analysed separately. Analysis of the experimental data reveals that additive and dominance effects are the main sources of variation among the 21 crosses of the $7 \times 7$ diallel. Comparisons of the $B_{1}$ and $B_{2}$ diallels also show that the single dosage dominance ( $h_{\mathrm{al}}$ type $)$ effects differ significantly from the double dosage dominance ( $h_{\mathrm{a} 2}$ type) effects. In addition, cytoplasmic control of amylose content is confirmed unambiguously and a large proportion of the heritable variation is shown to be controlled by a series of multiple alleles with large effects.
\end{abstract}

Keywords: amylose, cooking quality, endosperm traits, gene action, rice, triploid tissues.

\section{Introduction}

Amylose determines the cooking and milling quality of rice. Rice with intermediate levels of amylose cooks fluffy and remains soft while those with low amylose become sticky, moist and tender after boiling (Kumar \& Khush, 1988). There are strong regional preferences for various types of rice and consequently the breeders have to tailor varieties with specific levels of amylose to satisfy local demand. Inheritance of amylose content, on the other hand, is complex as it is transmitted disomically but expressed in a triploid phase (in the endosperm). Thus the standard diploid models cannot be applied to study its genetical control. Recently, several models (Gale, 1976; Huidong, 1987; Bogyo et al., 1988; Pooni et al., 1992) have been proposed which are specifically devised to study the inheritance of traits like amylose content. We have applied these models to investigate the genetical control of amylose content among ten sets of basic generations and shown that its expression is not only controlled by nuclear genes but also influenced by cytoplasmic effects and their inter-

*Correspondence. actions (Pooni et al., 1993). In the present paper we apply the same models to investigate the genetical control of amylose content among the early generations of a diallel set of crosses.

\section{Materials and methods}

The material is derived from seven elite inbred lines of indica rice which were chosen to represent the amylose levels preferred in the various regions of the world. The main features of these lines are shown in Table 1. These lines were selfed and crossed in all pairwise combinations at (IRRI) during 1985 (normal season). The reciprocal $F_{1}$ hybrids thus produced and the parental families were then raised in the following off season and selfed/crossed as shown in Table 2 to obtain large samples of seed of the 21 sets of basic generations. Random samples of these seeds were dehulled in a Satake machine and milled in a test tube mill. Embryos of individual seeds were then removed and the amylose level of each seed determined following Juliano (1971). The averaged amylose levels of various families are given in Table 3. 
Table 1 Main features of the inbred lines

\begin{tabular}{llll}
\hline Line & Abbreviation & $\begin{array}{l}\text { Amylose level } \\
(\%)\end{array}$ & Category \\
\hline IR8 & IR8 & 27 & High amylose \\
BPI121-401 & BPI & 25 & High amylose \\
IR24632-34 & IR246 & 22 & Intermediate amylose \\
IR24 & IR24 & 15 & Intermediate amylose \\
IR3351-38 & IR335 & 12 & Low amylose \\
IR37307 & IR307 & 7 & Low amylose \\
IR29 & IR29 & 0 & Waxy \\
\hline
\end{tabular}

Table 2 Crosses between parental lines and $F_{1}$ hybrids

\begin{tabular}{lllll}
\hline & \multicolumn{4}{l}{ Male parents } \\
Female & $\mathrm{P}_{1}$ & $\mathrm{P}_{2}$ & $\mathrm{~F}_{1}(1 \times 2)$ & $\mathrm{RF}_{1}(2 \times 1)$ \\
\hline $\mathrm{P}_{1}$ & Self & Cross & - & - \\
$\mathrm{P}_{2}$ & Cross & Self & - & - \\
$\mathrm{F}_{1}(1 \times 2)$ & Cross & Cross & Self & - \\
$\mathrm{RF}_{1}(2 \times 1)$ & Cross & Cross & - & Self \\
\hline
\end{tabular}

\section{Results}

\section{Diallel analysis of family means}

Although all sets of generations can be analysed as a single diallel following Gardener \& Eberhart (1966) we consider them as separate $\left(F_{1}, F_{2}\right.$ and $B_{1}$ and $\left.B_{2}\right)$ diallels for the sake of simplicity and the comparison of results across generations.

The theoretical basis of diallel analysis is well established for disomically inherited/expressed traits (Griffing, 1956; Dickinson \& Jinks, 1956; Hayman, 1954a, b, 1957, 1958; Jinks, 1954, 1955, 1956; Jinks \& Stevens, 1959; Jones, 1965). In the present case, although the character under study shows diploid inheritance it is, however, expressed in a triploid state. We therefore initially develop the theory for the new situation and establish if the analytical procedures of the diploid diallels can be applied to the present case as well.

Considering two alleles $A$ and $a$ at a locus, the two possible inbred lines have the genotypes $A A A$ and $a a a$, respectively. Their pairwise matings yield the expectations shown in Table 4 for the $F_{1}, F_{2}, B_{1}$ (hybrid $\times \mathrm{P}_{1}$ type of crosses) and $\mathrm{B}_{2}$ (hybrid $\times \mathrm{P}_{2}$ type of crosses) diallels (Gale, 1976; Pooni et al., 1992 for symbols and definitions). The first thing that becomes apparent is that the reciprocally produced $F_{1}$ crosses are expected to differ even in the absence of maternal/ cytoplasmic effects. Furthermore, the magnitude of these differences depends on the additive genetic deviations of the parental lines and the dominance effects $h_{\mathrm{a} 1}$ and $h_{\mathrm{a} 2}$. The standard analyses of diallel tables (e.g. Hayman, 1954b; Griffing, 1956) are still expected to apply under these situations but only to the full diallel.

The $F_{2}$ reciprocals, on the other hand, are not expected to differ except in the presence of cytoplasmic/maternal effects (see Pooni et al., 1992). Consequently we do not expect to detect reciprocal differences in the $F_{2}$ diallel as frequently as in the $F_{1}$ diallel and the corresponding meansquares of the two diallels may in fact differ significantly on many occasions.

Similarly, we do not expect reciprocal differences in the $B_{1}$ and $B_{2}$ diallels when maternal parents of various backcross families are kept the same (either $F_{1} s$ and $\mathrm{RF}_{l} \mathrm{~s}$ or the parental lines) and there are no cytoplas$\mathrm{mic} /$ maternal effects. Mixing of the maternal parents while producing hybrids and/or backcrosses, on the other hand, will induce heritable as well as extranuclear differences between reciprocals whose magnitude will depend collectively on the values of the additive, dominance, epistatic and cytoplasmic/maternal effects.

It is also apparent from the theory that estimates of the additive component are likely to be very similar across the $F_{1}, F_{2}, B_{1}$ and $B_{2}$ diallels except in the presence of genotype $\times$ environment interaction. The dominance component, however, can differ between diallels, particularly between those based on the $F_{1}$ and $F_{2}$ families, as the coefficients of the dominance parameters $\left(h_{\mathrm{a} 1}\right.$ and $\left.h_{\mathrm{a} 2}\right)$ differ considerably between these generations $\left(1 / 2 h_{\mathrm{a} 1}+1 / 2 h_{\mathrm{a} 2}\right.$ for $\mathrm{F}_{1}$ and $1 / 4 h_{\mathrm{a} 1}+1 / 4 h_{\mathrm{a} 2}$ for $\left.\mathrm{F}_{2}\right)$. The same component, on the other hand, will differ between the $B_{1}$ and the $B_{2}$ diallels not because of differences between coefficients but because $\mathrm{B}_{1}$ families often display $h_{\mathrm{a} 2}$ type whereas $\mathrm{B}_{2}$ exhibit $h_{\mathrm{a}}$ type of non-additive effects. Furthermore, the confounding of the additive genetic and 
Table 3 Average amylose contents of the seven parental lines (underlined), the reciprocally produced $F_{1}$ crosses and the $F_{2}$ and the first backcross $\left(B_{1}\right.$ and $\left.B_{2}\right)$ families derived from them

\begin{tabular}{lrrrrrrr}
\hline & IR29 & IR307 & IR335 & IR24 & IR246 & BPI & IR8 \\
\hline F, diallel & & & & & & & \\
IR29 & $0.01 \dagger$ & 1.51 & 5.70 & 5.59 & 21.02 & 22.92 & 23.88 \\
IR307 & 3.09 & $\underline{7.41}$ & 11.08 & 6.86 & 17.45 & 13.84 & 23.47 \\
IR335 & 6.10 & 7.88 & $\underline{12.61}$ & 9.45 & 23.70 & 23.28 & 26.28 \\
IR24 & 12.22 & 12.88 & 14.12 & $\underline{15.11}$ & 26.32 & 27.21 & 27.96 \\
IR246 & 22.43 & 15.91 & 24.61 & 21.78 & $\underline{21.74}$ & 22.85 & 25.61 \\
BPI & 22.40 & 18.65 & 23.91 & 24.47 & 23.60 & $\underline{24.89}$ & 26.43 \\
IR8 & 27.54 & 26.88 & 24.89 & 25.24 & 27.05 & 29.27 & $\underline{27.26}$ \\
$F_{2}$ diallel & & & & & & & \\
IR29 & - & 4.15 & 8.37 & 9.57 & 15.32 & 17.60 & 20.50 \\
IR307 & 3.09 & - & 12.05 & 9.46 & 12.77 & 14.84 & 22.21 \\
IR335 & 8.06 & 11.52 & - & 14.22 & 22.75 & 22.02 & 24.51 \\
IR24 & 9.60 & 10.65 & 14.19 & - & 20.08 & 22.72 & 24.60 \\
IR246 & 16.96 & 14.47 & 24.46 & 22.68 & - & 23.92 & 26.57 \\
BPI & 18.51 & 13.06 & 23.26 & 21.28 & 25.38 & - & 27.21 \\
IR8 & 19.71 & 20.29 & 23.28 & 23.80 & 24.61 & 25.19 & - \\
$B_{1}$ diallel & & & & & & & \\
IR29 & - & 5.10 & 6.10 & 7.18 & 19.25 & 21.96 & 23.33 \\
IR307 & 4.05 & - & 9.80 & 8.33 & 18.09 & 17.31 & 21.78 \\
IR335 & 9.58 & 10.51 & - & 11.20 & 22.89 & 24.12 & 25.03 \\
IR24 & 6.33 & 9.25 & 8.40 & - & 23.71 & 22.28 & 29.47 \\
IR246 & 16.75 & 16.70 & 20.31 & 21.76 & - & 18.79 & 27.11 \\
BPI & 22.50 & 19.77 & 24.69 & 21.22 & 22.05 & - & 30.28 \\
IR8 & 26.46 & 24.03 & 24.47 & 27.42 & 23.43 & 26.74 & - \\
$B_{2}$ diallel & & & & & & & \\
IR29 & - & 1.90 & 3.44 & 4.41 & 8.75 & 9.11 & 11.27 \\
IR307 & 2.04 & - & 6.32 & 7.10 & 12.05 & 9.73 & 16.23 \\
IR335 & 5.40 & 8.39 & - & 12.88 & 15.49 & 19.94 & 20.25 \\
IR24 & 3.62 & 6.74 & 13.75 & - & 16.61 & 19.90 & 19.58 \\
IR246 & 8.05 & 10.62 & 15.90 & 16.17 & - & 19.13 & 28.38 \\
BPI & 11.63 & 12.77 & 17.50 & 20.57 & 22.02 & - & 26.93 \\
IR8 & 12.42 & 14.06 & 18.31 & 18.93 & 22.53 & 25.72 & - \\
\hline & & & & & & &
\end{tabular}

$\dagger$ See Table 12 for family sizes.

Table 4 Expectations of various pairwise matings

\begin{tabular}{lllll}
\hline & & \multicolumn{2}{l}{ Crosses } & \\
\cline { 3 - 4 } Diallel & $A A A$ self & $A A A \times a a a$ & $a a a \times A A A$ & aaa self \\
\hline $\mathrm{F}_{1}$ & $m+d_{\mathrm{a}}$ & $m+1 / 3 d_{\mathrm{a}}+h_{\mathrm{a} 1}$ & $m-1 / 3 d_{\mathrm{a}}+h_{\mathrm{a} 2}$ & $m-d_{\mathrm{a}}$ \\
$\mathrm{F}_{2}$ & $m+d_{\mathrm{a}}$ & $m+1 / 4 h_{\mathrm{a} 1}+1 / 4 h_{\mathrm{a} 2}$ & $m+1 / 4 h_{\mathrm{a} 1}+1 / 4 h_{\mathrm{a} 2}$ & $m-d_{\mathrm{a}}$ \\
$\mathrm{B}_{1}$ & $m+d_{\mathrm{a}}$ & $m+1 / 3 d_{\mathrm{a}}+1 / 2 h_{\mathrm{a} 2}$ & $m+1 / 3 d_{\mathrm{a}}+1 / 2 h_{\mathrm{a} 2}$ & $m-d_{\mathrm{a}}$ \\
$\mathrm{B}_{2}$ & $m+d_{\mathrm{a}}$ & $m-1 / 3 d_{\mathrm{a}}+1 / 2 h_{\mathrm{a} 1}$ & $m-1 / 3 d_{\mathrm{a}}+1 / 2 h_{\mathrm{a} 1}$ & $m-d_{\mathrm{a}}$ \\
\hline
\end{tabular}

dominance effects in the $B_{1}$ and $B_{2}$ diallels renders the detection of dominance variation ineffective and these effects can only be separated by averaging the $B_{1}$ and $\mathrm{B}_{2}$ scores over the crosses ( $\mathrm{B}$ diallel).
The above observations are more or less confirmed by the analyses presented in Table 5 . These analyses further show that whereas all items determining the presence of additive and non-additive effects ( $a, b, b 1$, 
Table 5 Hayman's analysis of various sets of diallel families

\begin{tabular}{|c|c|c|c|c|c|c|c|c|c|c|c|}
\hline \multirow[b]{3}{*}{ Item } & \multirow[b]{3}{*}{ d.f. $\dagger$} & \multicolumn{10}{|l|}{ Diallel } \\
\hline & & \multicolumn{2}{|l|}{$\mathrm{F}_{1}$} & \multicolumn{2}{|l|}{$\mathrm{F}_{2}$} & \multicolumn{2}{|l|}{$\mathrm{B}_{1}$} & \multicolumn{2}{|l|}{$\mathrm{B}_{2}$} & \multicolumn{2}{|l|}{ B } \\
\hline & & $\mathrm{ms}$ & $\mathrm{F} \ddagger$ & $\mathrm{ms}$ & $\mathrm{F}$ & $\mathrm{ms}$ & $\mathrm{F}$ & $\mathrm{ms}$ & $\mathrm{F}$ & $\mathrm{ms}$ & $\mathrm{F}$ \\
\hline $\mathrm{a}$ & 6 & 425.47 & 3636 & 357.90 & 3999 & 391.43 & 3434 & 402.54 & 971 & 393.41 & 1434 \\
\hline $\mathrm{b}$ & 21 & 30.33 & 259 & 9.25 & 103 & 25.09 & 220 & 3.66 & 9 & 6.70 & 24 \\
\hline b1 & 1 & 79.78 & 682 & 30.90 & 345 & 53.44 & 467 & 20.50 & 50 & 2.28 & 8 \\
\hline b2 & 6 & 12.27 & 105 & 5.56 & 62 & 11.25 & 99 & 2.32 & 6 & 5.54 & 20 \\
\hline b3 & 14 & 34.55 & 295 & 9.28 & 104 & 29.01 & 254 & 3.03 & 7 & 7.94 & 29 \\
\hline c & 6 & 13.43 & 115 & 1.85 & 21 & 3.70 & 32 & 2.94 & 7 & 2.94 & 11 \\
\hline d & 15 & 1.86 & 16 & 0.67 & 7 & 2.04 & 18 & 1.78 & 4 & 1.57 & 6 \\
\hline Error & & 0.12 & & 0.09 & & 0.11 & & 0.41 & & 0.27 & \\
\hline (d.f.) & & (931) & & (16512) & & (3232) & & (3919) & & $(7151)$ & \\
\hline
\end{tabular}

$\dagger d, f$ for the $a, b, c$ and $d$ items are the same through out.

$\ddagger$ Each $F$ is significant at $P \leqslant 0.001$ (****).

Table 6 GCA values of the parental lines as estimated from the various diallels

\begin{tabular}{llllll}
\hline & \multicolumn{6}{l}{ Diallel } & & & & \\
\cline { 2 - 6 } Parent & \multicolumn{1}{l}{$\mathrm{F}_{1}$} & \multicolumn{1}{c}{$\mathrm{F}_{2}$} & \multicolumn{1}{c}{$\mathrm{B}_{1}$} & \multicolumn{1}{c}{$\mathrm{B}_{2}$} & $\mathrm{~B}$ \\
\hline IR29 & -6.24 & -6.70 & -6.73 & -8.13 & -7.15 \\
IR307 & -6.25 & -5.85 & -5.36 & -5.22 & -5.31 \\
IR335 & -2.54 & -0.81 & -2.12 & -0.94 & -1.50 \\
IR24 & -1.25 & -0.87 & -1.23 & -0.39 & -1.20 \\
IR246 & 3.86 & 3.44 & 3.32 & 3.09 & 2.95 \\
BPI & 4.77 & 4.25 & 4.56 & 4.92 & 4.97 \\
IR8 & 7.66 & 6.55 & 7.56 & 6.66 & 7.23 \\
\hline
\end{tabular}

b2 and b3) are highly significant against the withinfamily error in every diallel, including the one based on the averages of the backcross families ( $\mathrm{B}$ diallel), the meansquares of item a are remarkably similar (range $357.90-425.47$ ) and those of items b2 and b3 are considerably different across diallels. Similarly, the two items representing the reciprocal differences ( $c$ and $d$ ) are also highly significant throughout and the meansquare of item $c$ takes the largest value (13.43) for the $F_{1}$ diallel whereas those of item $d$ are more or less similar in magnitude across all the diallels. Comparisons of the appropriate meansquares across diallels by the model fitting procedure of Hayman (1960) further demonstrated that the various components are statistically equal between diallels with the exception of $\mathrm{b} 3$ which differs significantly between $F_{1}$ and $F_{2}$ $\left(\chi_{(1)}^{2}=4.65^{*}\right)$ and $\mathrm{B}_{1}$ and $\mathrm{B}_{2}$ diallels $\left(\chi_{(1)}^{2}=9.14^{* *}\right)$.

Table 6 further demonstrates the consistency of the results across diallels. The ranking of the parental lines according to their GCA values (obtained following Griffing, 1956) is virtually the same for all the diallels except in the case of $F_{2}$ where IR335 and IR24 swap their ranks. While such consistency is rarely observed in breeding experiments, it is however not surprising in the present case, firstly because the lines represent the whole range of amylose levels from 0 per cent to 28 per cent and, secondly the trait under study is highly heritable.

\section{Wr $/$ Vr relationships}

Table 7 shows the expectations of the array variances $\left(V r_{\mathrm{i}}\right)$ and array covariances $\left(W r_{\mathrm{i}}\right)$ for a single gene/two allele case where allele frequencies are assumed to be equal $(\mathrm{u}=\mathrm{v}=0.5)$ for the sake of simplicity. Theory shows that the $W r / V r$ relationships of Jinks (1954) would also hold for various diallels irrespective of the complexity of inheritance in the present case. Clearly, $W r_{\mathrm{i}}$ is expected to have a unit regression on $V r_{\mathrm{i}}$ and $W r_{\mathrm{i}}-V r_{\mathrm{i}}$ will remain constant across arrays in the absence of epistasis and gene correlation. However, it is also apparent that differences between array variances are likely to be small in several cases and this can lead to inaccurate ranking of the parental lines in the $W r / V r$ graph. In the present case, the ranking of parents is expected to be unreliable in the $\mathrm{B}_{2}$ diallel because $1 / 3 d_{\mathrm{a}}-1 / 2 h_{\mathrm{a} 1}$ is likely to take a small value due to $h_{\mathrm{a} 1}$ being positive in most crosses.

Table 8 shows that regression of $W r$ on $V r$ does not differ from unity in any case. The lowest value of $b$ $(=0.88 \pm 0.07)$ is observed for the $F_{1}$ diallel and all other values are higher than 0.94 . These results clearly indicate that either there is no epistasis and gene corre- 
Table $7 \quad W r V r$ relationships

\begin{tabular}{|c|c|c|}
\hline & Variance $\left(V r_{\mathrm{i}}\right)$ & Covariance $\left(W r_{\mathrm{i}}\right)$ \\
\hline $\begin{array}{l}F_{l} \text { diallel (full) } \\
\text { Array } A A A \\
\text { Array } a a a \\
\text { Array diff. } \\
W r_{\mathrm{i}}-V r_{\mathrm{i}} \text { for } A A A \\
\text { and } a a a \text { array }\end{array}$ & $\begin{array}{l}1 / 4\left(d_{\mathrm{a}}-1 / 2 h_{\mathrm{a} 1}-1 / 2 h_{\mathrm{a} 2}\right)^{2} \\
1 / 4\left(d_{\mathrm{a}}+1 / 2 h_{\mathrm{a} 1}+1 / 2 h_{\mathrm{a} 2}\right)^{2} \\
-1 / 2 d_{\mathrm{a}}\left(h_{\mathrm{a} 1}+h_{\mathrm{a} 2}\right) \\
\left(1 / 4 d_{\mathrm{a}}-1 / 2 h_{\mathrm{a} 1}-1 / 2 h_{\mathrm{a} 2}\right)\left(d_{\mathrm{a}}+1\right.\end{array}$ & $\begin{array}{l}1 / 2 d_{\mathrm{a}}\left(d_{\mathrm{a}}-1 / 2 h_{\mathrm{a} 1}-1 / 2 h_{\mathrm{a} 2}\right) \\
1 / 2 d_{\mathrm{a}}\left(d_{\mathrm{a}}+1 / 2 h_{\mathrm{a} 1}+1 / 2 h_{\mathrm{a} 2}\right) \\
-1 / 2 d_{\mathrm{a}}\left(h_{\mathrm{a} 1}+h_{\mathrm{a} 2}\right) \\
\left.1 / 2 h_{\mathrm{a} 1}+1 / 2 h_{\mathrm{a} 2}\right)\end{array}$ \\
\hline $\begin{array}{l}F_{l} \text { diallel (upper half) } \\
\text { Array } A A A \\
\text { Array aaa } \\
\text { Array diff. } \\
W r_{\mathrm{i}}-V r_{\mathrm{i}} \text { for } A A A \\
\text { and } a a a \text { array }\end{array}$ & $\begin{array}{l}\left(1 / 3 d_{\mathrm{a}}-1 / 2 h_{\mathrm{a} 1}\right)^{2} \\
\left(2 / 3 d_{\mathrm{a}}+1 / 2 h_{\mathrm{a} 1}\right)^{2} \\
-d_{\mathrm{a}}\left(1 / 3 d_{\mathrm{a}}+h_{\mathrm{a} 1}\right) \\
\left(1 / 3 d_{\mathrm{a}}-1 / 2 h_{\mathrm{a} 1}\right)\left(2 / 3 d_{\mathrm{a}}+1 / 2 h_{\mathrm{a} 1}\right.\end{array}$ & $\begin{array}{l}\left(1 / 3 d_{\mathrm{a}}^{2}-1 / 2 d_{\mathrm{a}} h_{\mathrm{a} 1}\right) \\
\left(2 / 3 d_{\mathrm{a}}^{2}+1 / 2 d_{\mathrm{a}} h_{\mathrm{a}}\right) \\
-d_{\mathrm{a}}\left(1 / 3 d_{\mathrm{a}}+h_{\mathrm{a} 1}\right)\end{array}$ \\
\hline $\begin{array}{l}F_{i} \text { diallel (lower half) } \\
\text { Array } A A A \\
\text { Array } a a a \\
\text { Array diff. } \\
W r_{\mathrm{i}}-V r_{\mathrm{i}} \text { for } A A A \\
\text { and } a a a \text { array }\end{array}$ & $\begin{array}{l}\left(2 / 3 d_{\mathrm{a}}-1 / 2 h_{\mathrm{a} 2}\right)^{2} \\
\left(1 / 3 d_{\mathrm{a}}+1 / 2 h_{\mathrm{a} 2}\right)^{2} \\
-d_{\mathrm{a}}\left(1 / 3 d_{\mathrm{a}}-h_{\mathrm{a} 2}\right) \\
\left(2 / 3 d_{\mathrm{a}}-1 / 2 h_{\mathrm{a} 2}\right)\left(1 / 3 d_{\mathrm{a}}+1 / 2 h_{\mathrm{a} 2}\right.\end{array}$ & $\begin{array}{l}\left(2 / 3 d_{\mathrm{a}}^{2}-1 / 2 d_{\mathrm{a}} h_{\mathrm{a} 2}\right) \\
\left(1 / 3 d_{\mathrm{a}}^{2}+1 / 2 d_{\mathrm{a}} h_{\mathrm{a} 2}\right) \\
-d_{\mathrm{a}}\left(1 / 3 d_{\mathrm{a}}-h_{\mathrm{a} 2}\right)\end{array}$ \\
\hline $\begin{array}{l}F_{2} \text { diallels (full \& half) } \\
\text { Array } A A A \\
\text { Array } a a a \\
\text { Array diff. } \\
W r_{\mathrm{i}}-V r_{\mathrm{i}} \text { for } A A A \\
\text { and } a a a \text { array }\end{array}$ & $\begin{array}{l}1 / 4\left(d_{\mathrm{a}}-1 / 4 h_{\mathrm{a} 1}-1 / 4 h_{\mathrm{a} 2}\right)^{2} \\
1 / 4\left(d_{\mathrm{a}}+1 / 4 h_{\mathrm{a} 1}+1 / 4 h_{\mathrm{a} 2}\right)^{2} \\
-1 / 4 d_{\mathrm{a}}\left(h_{\mathrm{a} 1}+h_{\mathrm{a} 2}\right) \\
\left(1 / 4 d_{\mathrm{a}}-1 / 4 h_{\mathrm{a} 1}-1 / 4 h_{\mathrm{a} 2}\right)\left(d_{\mathrm{a}}+h\right.\end{array}$ & $\begin{array}{l}1 / 2 d_{\mathrm{a}}\left(d_{\mathrm{a}}-1 / 4 h_{\mathrm{a} 1}-1 / 4 h_{\mathrm{a} 2}\right) \\
1 / 2 d_{\mathrm{a}}\left(d_{\mathrm{a}}+1 / 4 h_{\mathrm{a} 1}+1 / 4 h_{\mathrm{a} 2}\right) \\
-1 / 4 d_{\mathrm{a}}\left(h_{\mathrm{a} 1}+h_{\mathrm{a} 2}\right) \\
\left.h_{\mathrm{a} 1}+h_{\mathrm{a} 2}\right)\end{array}$ \\
\hline $\begin{array}{l}B_{l} \text { diallels (full \& half) } \\
\text { Array } A A A \\
\text { Array } a a a \\
\text { Array diff. } \\
W r_{\mathrm{i}}-V r_{\mathrm{i}} \text { for } A A A \\
\text { and } a a a \text { array }\end{array}$ & $\begin{array}{l}\left(1 / 3 d_{\mathrm{a}}-1 / 4 h_{\mathrm{a} 2}\right)^{2} \\
\left(2 / 3 d_{\mathrm{a}}+1 / 4 h_{\mathrm{a} 2}\right)^{2} \\
-d_{\mathrm{a}}\left(1 / 3 d_{\mathrm{a}}+1 / 2 h_{\mathrm{a} 2}\right) \\
\left(1 / 3 d_{\mathrm{a}}-1 / 4 h_{\mathrm{a} 2}\right)\left(2 / 3 d_{\mathrm{a}}+1 / 4 h_{\mathrm{a} 2} 2\right.\end{array}$ & $\begin{array}{l}d_{\mathrm{a}}\left(1 / 3 d_{\mathrm{a}}-1 / 4 h_{\mathrm{a} 2}\right) \\
d_{\mathrm{a}}\left(2 / 3 d_{\mathrm{a}}+1 / 4 h_{\mathrm{a} 2}\right) \\
-d_{\mathrm{a}}\left(1 / 3 d_{\mathrm{a}}+1 / 2 h_{\mathrm{a} 2}\right) \\
\left.{ }_{\mathrm{a} 2}\right)\end{array}$ \\
\hline $\begin{array}{l}B_{2} \text { diallels (full \& half) } \\
\text { Array } A A A \\
\text { Array aaa } \\
\text { Array diff. } \\
W r_{\mathrm{i}}-V r_{\mathrm{i}} \text { for } A A A \\
\text { and } a a a \text { array }\end{array}$ & $\begin{array}{l}\left(2 / 3 d_{\mathrm{a}}-1 / 4 h_{\mathrm{al}}\right)^{2} \\
\left(1 / 3 d_{\mathrm{a}}+1 / 4 h_{\mathrm{a} 1}\right)^{2} \\
d_{\mathrm{a}}\left(1 / 3 d_{\mathrm{a}}-1 / 2 h_{\mathrm{a} 1}\right) \\
\left(2 / 3 d_{\mathrm{a}}-1 / 4 h_{\mathrm{a} 1}\right)\left(1 / 3 d_{\mathrm{a}}+1 / 4 h_{\mathrm{a}}\right.\end{array}$ & $\begin{array}{l}d_{\mathrm{a}}\left(2 / 3 d_{\mathrm{a}}-1 / 4 h_{\mathrm{a} 1}\right) \\
d_{\mathrm{a}}\left(1 / 3 d_{\mathrm{a}}+1 / 4 h_{\mathrm{a} 1}\right) \\
d_{\mathrm{a}}\left(1 / 3 d_{\mathrm{a}}-1 / 2 h_{\mathrm{a} 1}\right)\end{array}$ \\
\hline $\begin{array}{l}B \text { diallels (full \& half) } \\
\text { Array } A A A \\
\text { Array aaa } \\
\text { Array diff. } \\
W r_{\mathrm{i}}-V r_{\mathrm{i}} \text { for } A A A \\
\text { and } a a a \text { array }\end{array}$ & $\begin{array}{l}1 / 4\left(d_{\mathrm{a}}-1 / 4 h_{\mathrm{a} 1}-1 / 4 h_{\mathrm{a} 2}\right)^{2} \\
1 / 4\left(d_{\mathrm{a}}+1 / 4 h_{\mathrm{a} 1}+1 / 4 h_{\mathrm{a} 2}\right)^{2} \\
-1 / 4 d_{\mathrm{a}}\left(h_{\mathrm{a} 1}+h_{\mathrm{a} 2}\right) \\
1 / 4\left(d_{\mathrm{a}}-1 / 4 h_{\mathrm{a} 1}-1 / 4 h_{\mathrm{a} 2}\right)\left(d_{\mathrm{a}}\right.\end{array}$ & $\begin{array}{l}1 / 2 d_{\mathrm{a}}\left(d_{\mathrm{a}}-1 / 4 h_{\mathrm{a} 1}-1 / 4 h_{\mathrm{a} 2}\right) \\
1 / 2 d_{\mathrm{a}}\left(d_{\mathrm{a}}+1 / 4 h_{\mathrm{a} 1}+1 / 4 h_{\mathrm{a} 2}\right) \\
-1 / 4 d_{\mathrm{a}}\left(h_{\mathrm{a} 1}+h_{\mathrm{a} 2}\right) \\
\left.h_{\mathrm{a} 1}+h_{\mathrm{a} 2}\right)\end{array}$ \\
\hline
\end{tabular}

lation or their effects are cancelled out. Positive and significant value of intercept $a$ for each regression further shows that the averaged dominance effects $\left(1 / 2 h_{\mathrm{a} 1}+1 / 2 h_{\mathrm{a} 2}\right)$ of each locus are smaller in magnitude than the corresponding additive effects $\left(d_{\mathrm{a}}\right)$. Ranking of the parents according to their dominance potentials (following Jinks, 1954) further indicates that the level of dominance varies among the lines and consequently their additive and non-additive rankings do not show a perfect agreement.

Furthermore, $W r / V r$ analysis of $\mathrm{B}_{1}$ diallel yields a markedly different ranking of the parental lines compared with other diallels. In fact, the ranking is reversed completely indicating clearly that differences between 
diallels cannot be explained merely by invoking reduced deviations among the $V r_{\mathrm{i}}$ values. This perhaps means that dominance is not completely unidirectional across the whole spectrum of crosses and reciprocal deviations may also be having a marked effect on the ranks of the parents.

Table 8 Regression of $W r$ on $V r$ and the ranking of the parental lines for the $F_{1}, F_{2}, B_{1}, B_{2}$ and $B$ diallels

\begin{tabular}{|c|c|c|c|c|c|}
\hline \multirow{2}{*}{$\begin{array}{l}\text { Statistic/ } \\
\text { line }\end{array}$} & \multicolumn{5}{|l|}{ Diallel } \\
\hline & $\mathrm{F}_{1}$ & $F_{2}$ & $\mathrm{~B}_{1}$ & $\mathrm{~B}_{2}$ & $\mathrm{~B}$ \\
\hline \multicolumn{6}{|c|}{ Regression of Wr on $\mathrm{Vr}$} \\
\hline Intercept a & 12.24 & 18.46 & 12.54 & 23.40 & 21.98 \\
\hline Regression $b$ & $\begin{array}{c}0.88 \\
\pm 0.07\end{array}$ & $\begin{array}{c}1.00 \\
\pm 0.04\end{array}$ & $\begin{array}{c}0.93 \\
\pm 0.06\end{array}$ & $\begin{array}{c}0.95 \\
\pm 0.05\end{array}$ & $\begin{array}{c}0.94 \\
\pm 0.04\end{array}$ \\
\hline$t_{(1-b)}$ & ns & ns & ns & ns & ns \\
\hline \multicolumn{6}{|c|}{ Ranking of parents } \\
\hline IR29 & 7 & 7 & 7 & 2 & 7 \\
\hline IR307 & 4 & 4 & 4 & 1 & 4 \\
\hline IR335 & 6 & 6 & 5 & 3 & 5 \\
\hline IR24 & 5 & 5 & 6 & 6 & 6 \\
\hline IR246 & 2 & 3 & 2 & 5 & 2 \\
\hline BPI & 3 & 2 & 3 & 7 & 3 \\
\hline IR8 & 1 & 1 & 1 & 4 & 1 \\
\hline
\end{tabular}

$\mathrm{ns}=P>0.05$.

\section{Components of means}

The above problem is further analysed by estimating the additive genetic $[d]$, dominance $[h]$ $\left(=1 / 2[h]_{1}+1 / 2[h]_{2}\right)$ and maternal $[c]$ components (see Pooni et al., 1992 for definitions) using the following orthogonal comparisons (Table 9) and investigating their relationships with each other. While the estimates given in Table 10 are obtained for each cross separately their confidence intervals are calculated from the overall variances that are presented as error meansquares in Table 5 . These confidence intervals are

Table 9 Orthogonal comparisons for estimating components [d], [h] and [c]

\begin{tabular}{lccc}
\hline & \multicolumn{2}{c}{ Orthogonal comparisons } \\
\cline { 2 - 4 } Family & {$[d]$} & {$[h]$} & {$[c]$} \\
\hline $\mathrm{F}_{1}$ & $1 / 2$ & 1 & 0 \\
$\mathrm{RF}_{1}$ & $-1 / 2$ & 1 & 0 \\
$\mathrm{~F}_{2}$ & $-1 / 2$ & $-1 / 2$ & 0 \\
$\mathrm{RF}_{2}$ & $1 / 2$ & $-1 / 2$ & 0 \\
$\mathrm{~B}_{1}$ & $1 / 2$ & $-1 / 4$ & $1 / 4$ \\
$\mathrm{RB}_{1}$ & $1 / 2$ & $-1 / 4$ & $-1 / 4$ \\
$\mathrm{~B}_{2}$ & $-1 / 2$ & $-1 / 4$ & $1 / 4$ \\
$\mathrm{RB}_{2}$ & $-1 / 2$ & $-1 / 4$ & $-1 / 4$ \\
\hline
\end{tabular}

Table 10 Orthogonal estimates of the additive, dominance and maternal components for various crosses

\begin{tabular}{|c|c|c|c|c|c|c|}
\hline & IR307 & IR335 & IR24 & IR246 & BPI & IR8 \\
\hline \multicolumn{7}{|c|}{ Additive component [d] } \\
\hline IR29 & 3.93 & 3.78 & 6.04 & 9.49 & 11.15 & 15.28 \\
\hline IR307 & & 1.43 & 4.29 & 4.44 & 10.59 & 10.43 \\
\hline IR335 & & & -1.17 & 5.51 & 5.38 & 5.39 \\
\hline IR24 & & & & 2.78 & 0.87 & 8.23 \\
\hline IR246 & & & & & -0.51 & 1.52 \\
\hline BPI & & & & & & 4.62 \\
\hline \multicolumn{7}{|c|}{ Dominance component [h] } \\
\hline IR29 & -2.30 & -2.55 & 2.84 & 14.11 & 10.97 & 14.95 \\
\hline IR307 & & -1.61 & 1.83 & 5.38 & 3.65 & 10.08 \\
\hline IR335 & & & -2.20 & 6.06 & 2.99 & 5.26 \\
\hline IR24 & & & & 7.16 & 8.69 & 5.15 \\
\hline IR246 & & & & & 1.31 & 1.71 \\
\hline BPI & & & & & & 2.09 \\
\hline \multicolumn{7}{|c|}{ Maternal component $[c]$} \\
\hline IR29 & -0.23 & 1.36 & -0.41 & -0.80 & 0.77 & 1.07 \\
\hline IR307 & & 0.70 & 0.14 & -0.71 & 1.38 & 0.02 \\
\hline IR335 & & & -0.48 & -0.54 & -0.47 & -0.63 \\
\hline IR24 & & & & -0.60 & -0.10 & -0.68 \\
\hline IR246 & & & & & 1.54 & -2.38 \\
\hline BPI & & & & & & -1.19 \\
\hline
\end{tabular}


\pm 0.52 for $[c], \pm 1.20$ for $[d]$ and \pm 1.18 for $[h]$ respectively.

Clearly all the $[h]$ values, all except two $[d]$ values $(-0.51$ and -1.17$)$ and 14 out of $21[c]$ values (magnitude $\geqslant 0.52$ ) are larger than their corresponding confidence limits and therefore can be assumed significant. Furthermore, all significant values of $[d]$ are positive suggesting that our classification of the high and the low-scoring parents $\left(\mathrm{P}_{1}\right.$ and $\left.\mathrm{P}_{2}\right)$ has been correct, particularly when the reciprocal effects are known to be significant in many crosses. Similarly, our earlier comments on the direction of dominance are also confirmed by the estimates of $[h]$ which are negative for four crosses (involving lines with the lowest amylose contents) and positive for the rest. Clearly the negative values of $[h]$ must have affected the magnitudes of $V r_{i}$ in such a way that their ranks are changed and this may have led to differences in the additive and the nonadditive rankings of the parental lines.

Interpretation of the 21 values of $[c]$, on the other hand, is rather difficult as a large proportion of these differences may be attributed to the transient effects of maternal nourishment which often varies with seasons and seed source. Consequently we obtained the mean maternal contribution of each line by averaging the maternal effects of those crosses where it was used as a female parent. As these effects are expected to persist over crosses, and presumably across seasons as well, they can be interpreted as cytoplasmic contributions of various parents (Table 11). The estimates in Table 11 suggest that maternal background does indeed influence the level of amylose in rice but only to a limited extent.

\section{Within-family variances}

Table 12 shows the within-family variances of various generations and the number of observations on which these variances are based. Under normal circumstances we do not expect the parental and $F_{1}$ variances to differ from each other because they all provide a measure of environmental variation. However, on many occasions these variances are affected by the differential environmental sensitivities of the genotypes and even by the maternal background which make them heterogeneous. Indeed, that is what was observed when we applied Bartlett's test to determine if these variances were homogeneous or not (chisquared $_{(48)}=392.54^{* * * *}$ is highly significant). Partitioning this chi-squared into its various components (see Table 13) further revealed that more than 91 per cent of the total variability was from specific differences between crosses and their reciprocals (chi$\left.\operatorname{squared}_{(36)}=359.2 * * *\right) \quad$ while maternal arrays accounted for only about 5 per cent (but significant) and paternal arrays even less.

A non-significant correlation between the means and variances of various families $\left(r_{(47 \text { d.f. })}=0.22^{\text {n.s. }}\right)$ and

Table 11 Average cytoplasmic effects of various parental lines

\begin{tabular}{llllllll}
\hline Variety & IR29 & IR307 & IR335 & IR24 & IR246 & BPI & IR8 \\
\hline $\begin{array}{l}\text { Cytoplasmic } \\
\text { effect }\end{array}$ & -0.25 & -0.25 & 0.60 & 0.09 & -0.26 & 0.62 & -0.54 \\
\hline
\end{tabular}

Table 12 Within-family variances of various generations/crosses

\begin{tabular}{llccccccc}
\hline & & IR29 & IR307 & IR335 & IR24 & IR246 & BPI & IR8 \\
\hline F, diallel & & & & & & & & \\
IR29 & Var & 0.002 & 0.40 & 1.83 & 1.04 & 1.30 & 1.79 & 7.11 \\
& $n$ & 20 & 20 & 20 & 20 & 20 & 20 & 20 \\
IR307 & Var & 0.52 & 3.31 & 2.57 & 2.57 & 2.86 & 2.72 & 1.66 \\
& $n$ & 20 & 20 & 20 & 20 & 20 & 20 & 20 \\
IR335 & Var & 1.93 & 0.87 & 1.11 & 0.80 & 6.74 & 3.11 & 2.49 \\
& $n$ & 20 & 20 & 20 & 20 & 20 & 20 & 20 \\
IR24 & Var & 1.36 & 2.16 & 4.35 & 0.82 & 0.29 & 0.93 & 0.90 \\
& $n$ & 20 & 20 & 20 & 20 & 20 & 20 & 20 \\
IR246 & Var & 2.38 & 2.37 & 1.86 & 5.56 & 0.10 & 2.41 & 1.49 \\
& $n$ & 20 & 20 & 20 & 20 & 20 & 20 & 20 \\
BPI & Var & 6.00 & 1.15 & 3.28 & 4.38 & 5.61 & 0.13 & 1.55 \\
& $n$ & 20 & 20 & 20 & 20 & 20 & 20 & 20 \\
IR8 & Var & 2.23 & 1.47 & 3.45 & 2.22 & 1.27 & 1.64 & 0.81 \\
& $n$ & 20 & 20 & 20 & 20 & 20 & 20 & 20
\end{tabular}


Table 12 Continued

\begin{tabular}{|c|c|c|c|c|c|c|c|c|}
\hline & & IR29 & IR307 & IR335 & IR24 & IR246 & BPI & IR8 \\
\hline \multicolumn{9}{|c|}{$F_{2}$ diallel } \\
\hline \multirow[t]{2}{*}{ IR29 } & Var & - & 7.02 & 27.20 & 34.60 & 107.77 & 100.48 & 149.02 \\
\hline & $n$ & & 386 & 388 & 431 & 460 & 392 & 390 \\
\hline \multirow[t]{2}{*}{ IR307 } & Var & 5.52 & - & 13.03 & 17.26 & 46.94 & 40.02 & 68.35 \\
\hline & $n$ & 398 & & 400 & 324 & 396 & 400 & 404 \\
\hline \multirow[t]{2}{*}{ IR335 } & Var & 27.60 & 12.53 & - & 6.75 & 24.37 & 25.06 & 40.62 \\
\hline & $n$ & 392 & 399 & & 392 & 396 & 402 & 393 \\
\hline \multirow[t]{2}{*}{ IR24 } & Var & 41.78 & 14.62 & 1.16 & - & 20.41 & 15.61 & 30.26 \\
\hline & $n$ & 426 & 398 & 374 & & 402 & 378 & 415 \\
\hline \multirow[t]{2}{*}{ IR246 } & Var & 112.04 & 41.97 & 22.12 & 30.17 & - & 4.99 & 9.85 \\
\hline & $n$ & 399 & 415 & 432 & 398 & & 409 & 409 \\
\hline \multirow[t]{2}{*}{ BPI } & Var & 112.31 & 36.59 & 29.08 & 13.11 & 5.82 & - & 11.46 \\
\hline & $n$ & 402 & 390 & 400 & 302 & 275 & & 393 \\
\hline \multirow[t]{2}{*}{ IR8 } & Var & 123.79 & 78.19 & 30.47 & 27.75 & 2.91 & 11.26 & - \\
\hline & $n$ & 404 & 365 & 398 & 396 & 296 & 402 & \\
\hline \multicolumn{9}{|c|}{$B_{1}$ diallel } \\
\hline \multirow[t]{2}{*}{ IR29 } & Var & - & 6.50 & 15.77 & 18.78 & 5.80 & 4.35 & 11.55 \\
\hline & $n$ & & 86 & 69 & 65 & 73 & 87 & 86 \\
\hline \multirow[t]{2}{*}{ IR307 } & Var & 6.06 & - & 4.28 & 8.72 & 31.12 & 21.80 & 17.53 \\
\hline & $n$ & 65 & & 78 & 78 & 76 & 50 & 96 \\
\hline \multirow[t]{2}{*}{ IR335 } & Var & 8.52 & 3.39 & - & 5.79 & 3.46 & 2.18 & 4.90 \\
\hline & $n$ & 132 & 92 & & 98 & 101 & 86 & 91 \\
\hline \multirow[t]{2}{*}{ IR24 } & Var & 16.74 & 8.25 & 3.45 & - & 8.26 & 5.87 & 11.51 \\
\hline & $n$ & 80 & 81 & 97 & & 80 & 98 & 100 \\
\hline \multirow[t]{2}{*}{ IR246 } & Var & 5.89 & 39.80 & 5.51 & 4.20 & - & 3.53 & 6.66 \\
\hline & $n$ & 87 & 74 & 98 & 100 & & 73 & 100 \\
\hline \multirow[t]{2}{*}{ BPI } & Var & 2.50 & 18.57 & 2.74 & 8.41 & 7.24 & - & 9.39 \\
\hline & $n$ & 69 & 100 & 100 & 99 & 110 & & 99 \\
\hline \multirow[t]{2}{*}{ IR8 } & Var & 0.24 & 10.41 & 6.15 & 5.91 & 7.38 & 7.92 & - \\
\hline & $n$ & 94 & 89 & 100 & 86 & 100 & 95 & \\
\hline \multicolumn{9}{|c|}{$B_{2}$ diallel } \\
\hline \multirow[t]{2}{*}{ IR29 } & Var & - & 2.89 & 15.77 & 24.58 & 90.51 & 134.30 & 150.46 \\
\hline & $n$ & & 91 & 80 & 89 & 68 & 94 & 77 \\
\hline \multirow[t]{2}{*}{ IR307 } & Var & 2.96 & - & 9.52 & 2.24 & 47.22 & 39.12 & 92.79 \\
\hline & $n$ & 88 & & 81 & 84 & 78 & 43 & 113 \\
\hline \multirow[t]{2}{*}{ IR335 } & Var & 26.48 & 3.84 & - & 6.44 & 41.26 & 55.85 & 59.13 \\
\hline & $n$ & 100 & 95 & & 103 & 94 & 97 & 101 \\
\hline \multirow[t]{2}{*}{ IR24 } & Var & 13.31 & 6.74 & 5.72 & - & 26.16 & 21.09 & 55.74 \\
\hline & $n$ & 80 & 97 & 100 & & 99 & 100 & 99 \\
\hline \multirow[t]{2}{*}{ IR246 } & Var & 84.62 & 39.31 & 46.36 & 29.21 & - & 7.29 & 15.44 \\
\hline & $n$ & 72 & 113 & 105 & 100 & & 74 & 89 \\
\hline BPI & Var & 134.97 & 29.74 & 31.38 & 20.57 & 4.98 & - & 17.26 \\
\hline & $n$ & 84 & 104 & 100 & 100 & 101 & & 99 \\
\hline IR8 & Var & 169.86 & 112.11 & 57.06 & 51.25 & 7.81 & 11.28 & - \\
\hline & $n$ & 75 & 100 & 77 & 100 & 60 & 124 & \\
\hline
\end{tabular}

a similar association between these statistics for the maternal arrays $\left(r_{(5 \text { d.f. })}=0.32^{\text {n.s. }}\right)$ further suggest that neither the heterogeneity among the parental and $F_{1}$ variances nor the overall sensitivity of the parental lines has orginated from scalar effects.
Genetic segregation, on the other hand, should make the variances of the $F_{2}, B_{1}$ and $B_{2}$ generations larger than those of the parental/ $F_{1}$ families and that is what we observe when we compare the average variances of the $\quad F_{1}(=2.22), \quad F_{2}(=37.66), \quad B_{1}(=9.22) \quad$ and 
$\mathrm{B}_{2}(=42.97)$ diallels. A comparatively smaller value of the $B_{1}$ variance (compared with the $B_{2}$ variance) further indicates that dominance is mainly towards the higher score but its significance against the $F_{1}$ variance also suggests that either dominance is mostly partial or alleles are dispersed among the parents. A positive and large difference between the combined variances of the backcross $\left(B_{1}+B_{2}\right)$ and the filial $\left(F_{1}+F_{2}\right)$ generations provides additional evidence of the extent of dominance variation that is prevailing in this material.

Theory further shows that, when allele frequencies are equal and there is no epistasis/linkage disequilibrium, the averaged within-variances of various arrays are expected to remain constant even when the variances of various crosses differ significantly. It can also be seen that these averaged within-variances will correlate linearly with the array means when the allele frequencies are not equal and the same statistics may display a quadratic relationship when the character under study is controlled by multiple alleles.

We initially test if the variances differ between crosses and whether their averages over arrays remain constant. We carry out these tests separately for the $F_{2}$, $\mathrm{B}_{1}$ and $\mathrm{B}_{2}$ diallels by subjecting their variances to Griffing's analysis (method 3, full diallel without selfs) and testing the significance of the GCA and the SCA mean squares against the reciprocals meansquare. Table 14 shows that both items are highly significant in all the cases implying that either allele frequencies are not equal or amylose content is controlled by multiple

Table 13 Bartlett's tests of homogeneity for the withinfamily variances of the parental and $F_{1}$ generations

\begin{tabular}{lrrl}
\hline Item & d.f. & \multicolumn{1}{c}{$X^{2}$} & Significance \\
\hline Maternal arrays & 6 & 21.00 & $* *$ \\
Paternal arrays & 6 & 12.34 & ns \\
M $\times$ P interaction & 36 & 359.20 & $* * *$ \\
\hline
\end{tabular}

ns $P>0.05 ; * 0.05 \geqslant P>0.01 ; * * 0.01 \geqslant P>0.001 ; * * *$

$P \leqslant 0.001$. alleles. That the latter explanation is more plausible is apparently confirmed by the analysis in Table 15 where the quadratic deviations of the $F_{2}$ array means (from their overall mean) are found to correlate significantly with the averaged array variances of the $F_{2}$ and the $B_{2}$ diallels.

Another property of multiple alleles is that they lead to a high correlation between the within-cross variances and parental diversity $([d])$. Similarly, correlation between the within-family variance and the $[h]$ component is expected to be unity when variation is controlled either by a single locus (with or without multiple alleles) or by a set of tightly linked loci. The estimates of $r$ for the $\mathrm{F}_{2}$ and $\mathrm{B}_{2}$ diallels further confirm that the genetic variability displayed by various crosses is primarily due to the segregation of a few alleles with large effects (Table 16).

\section{Discussion}

The main conclusion that we draw from the theoretical developments is that the standard analyses of diallel tables are as applicable to the present case as they are

Table 15 Correlations between array means and averaged array variances

\begin{tabular}{llccc}
\hline & & \multicolumn{3}{c}{ Averaged array variances } \\
\cline { 3 - 5 } Array & $\mathrm{F}_{2}$ Array mean & $\mathrm{F}_{2}$ diallel & $\mathrm{B}_{1}$ diallel & $\mathrm{B}_{2}$ diallel \\
\hline IR29 & 10.82 & 77.38 & 6.96 & 76.48 \\
IR307 & 11.67 & 30.67 & 16.27 & 29.44 \\
IR335 & 16.70 & 18.46 & 4.93 & 28.27 \\
IR24 & 16.65 & 17.81 & 8.37 & 17.93 \\
IR246 & 20.96 & 35.40 & 12.98 & 36.26 \\
BPI & 21.77 & 33.04 & 8.45 & 45.66 \\
IR8 & 24.07 & 50.86 & 6.58 & 68.85 \\
r(xy) & & $-0.21 \mathrm{~ns}$ & $-0.24 \mathrm{~ns}$ & $0.09 \mathrm{~ns}$ \\
r(x $\left.{ }^{2} \mathrm{y}\right)$ & & $0.84^{*}$ & $0.12 \mathrm{~ns}$ & $0.83^{*}$ \\
\hline
\end{tabular}

†See Table 13 for probability levels.

Table 14 Griffing's analysis of the $F_{2}, B_{1}$ and $B_{2}$ variances of the $7 \times 7$ diallel

\begin{tabular}{|c|c|c|c|c|c|c|c|}
\hline \multirow[b]{2}{*}{ Item } & \multirow[b]{2}{*}{ d.f. } & \multicolumn{2}{|l|}{$\mathrm{F}_{2}$ diallel } & \multicolumn{2}{|c|}{$\mathrm{B}_{1}$ diallel } & \multicolumn{2}{|l|}{$\mathrm{B}_{2}$ diallel } \\
\hline & & $\mathrm{ms}$ & $\mathrm{F}^{\dagger}$ & $\mathrm{ms}$ & $F$ & $\mathrm{~ms}$ & $\mathrm{~F}$ \\
\hline GCA & 6 & 4315.60 & $139^{* * *}$ & 118.49 & $13^{* * *}$ & 5059.38 & $107^{* * *}$ \\
\hline SCA & 14 & 2169.38 & $70^{* * * *}$ & 112.55 & $12^{* * *}$ & 3371.62 & $71^{* * * *}$ \\
\hline Recips & 21 & 30.99 & & 9.72 & & 47.34 & \\
\hline
\end{tabular}

†See Table 13 for probability level. 
Table 16 Correlations between the components of means and the within-family variance of the $F_{2}, B_{1}$ and $B_{2}$ generations

\begin{tabular}{lllc}
\hline Statistics & Correlation $(r)$ & Statistics & Correlation $(r)$ \\
\hline$[d] \& \mathrm{~F}_{2}$ variance & $0.87^{*}$ & {$[h] \& \mathrm{~F}_{2}$ variance } & $0.84^{*} \dagger$ \\
{$[d] \& \mathrm{~B}_{1}$ variance } & 0.11 & {$[h] \& \mathrm{~B}_{1}$ variance } & -0.01 \\
{$[d] \& \mathrm{~B}_{2}$ variance } & $0.87^{*}$ & {$[h] \& \mathrm{~B}_{2}$ variance } & $0.84^{*}$ \\
\hline
\end{tabular}

$\nmid$ See Table 13 for probability levels.

to situations where characters show disomic inheritance/expression. Consequently, not only can the additive and non-additive effects be detected and estimated but the nature of non-additive variation can also be determined using $W r / V r$ analysis. Similarly, one can estimate various components and use them for determining heritability and dominance ratio etc.

However, the interpretation of results is considerably different in the present case. For example, dominance components of the above analyses include both the $h_{\mathrm{a} 1}$ and $h_{\mathrm{a} 2}$ types of variation and therefore cannot provide information on their relative contributions. Furthermore, it is not at all possible to separate these effects even if we carry out a combined analysis of all the basic generations. Similarly, the results of various diallels can differ even when the simple additive/ dominance model is adequate. For instance, reciprocal differences are expected to be significant in an $F_{1}$ diallel even in the absence of reciprocal/maternal effects. The backcross families will also show such differences when both $F_{1} s$ and parental lines are used as female parents for producing the reciprocal families. Thus, only an $F_{2}$ diallel can be trusted to provide unbiased tests of the reciprocal effects under most situations

Another theoretical point concerns the comparative efficiency of various diallels. Clearly the $F_{1}$ diallel is the most efficient for detecting and estimating the components of additive and dominance variation and for ranking the parents according to their general combining ability and dominance effects. However, its within-family variances do not provide any supplementary information on the genetical control of the trait owing to lack of segregation. $\mathrm{B}_{1}$ and $\mathrm{B}_{2}$ diallels, on the other hand, do not provide an independent test of dominance as the additive and dominance effects are confounded in the non-additive component. In addition, both of these diallels can yield unreliable ranking of parents in the $\mathrm{Wr} / \mathrm{Vr}$ graph. After considering these problems and those associated with the tests of reciprocal effects and of hybrid seed production, we find that $F_{2}$ diallel is perhaps the most appropriate for analysing traits like amylose content.
The results of Tables 5 and 6 generally support the above theoretical points and in addition show that all the important sources of variation, namely additive and non-additive genetic and maternal/non-nuclear, contribute significantly to the variability between family means. While these results confirm mainly the stratified nature of the sample and what we already know about the inheritance of amylose content from previous studies, what is most surprising is the failure of $\mathrm{Wr} / \mathrm{Vr}$ analysis to detect epistasis (Table 8 ) whose presence is reported by Pooni et al. (1993) in at least nine of the crosses included in the present study. Apparently there are several explanations for this discrepancy and one of the most commonly used is that the effects of epistasis and gene correlation are cancelled out. This is perhaps a valid explanation for the present case as duplicate epistasis is shown to prevail in the material under study (Pooni et al., 1993) and stratification often results in linkage disequilibrium for alleles in coupling. It is however equally possible that the $W r / V r$ relationship is appreciably less efficient in detecting epistasis than the scaling tests, particularly when data from various generations are treated as separate diallels.

Finally, we have used the within-family variances for the first time to establish if several loci are involved in the control of amylose content and whether multiple alleles are present at these loci. While these conclusions are obviously valid in the present case (as they are supported by some independent evidence for the multiallelic control of amylose content), the same however is unlikely to be true in many cases because the results of such analyses are amenable to more than one interpretation.

\section{Acknowledgements}

These are due to Dr M. J. Kearsey for criticism of the manuscript and the Association of Commonwealth Universities for the award of an ACU Fellowship to I.K. The statistical analysis was carried out on the University of Birmingham Mainframe Computer. 


\section{References}

BOGYO, T. P., LANCE, R. C. M., CHEVALIER, P. AND NILAN, R. A. 1988. Genetic models for quantitatively inherited endosperm characters. Heredity, 60, 61-67.

DICKINSON, A. G. AND JINKS, J. L. 1986. A generalised analysis of diallel crosses. Genetics, 41, 65-78.

GALE, M. D. 1976. High alpha amylase breeding and genetical aspects of the problem. Cereal Res. Comm., 4, 231-243.

GARDENER, C. O. AND EBERHART, S. A. 1966. Analysis and interpretation of the variety diallel and related populations. Biometrics, 22, 439-452.

GRIFFING, B. 1956. Concept of general and specific combining ability in relation to diallel crossing systems. Aust. J. Biol. Sci., 9, 463-493.

HAYMAN, B. I. 1954a. The theory and analysis of diallel crosses. Genetics, 39, 789-809.

HAYMAN, B. I. 1954b. The analysis of variance of diallel tables. Biometrics, 10, 235-244.

HAYMAN, B. I. 1957. Interaction, heterosis and diallel crosses. Genetics, 42, 336-355.

HAYMAN, B. I. 1958. The theory and analysis of diallel crosses. Genetics, 43, 65-85.

HAYMAN, B. I. 1960. Maximum likelihood estimation of genetic components of variation. Biometrics, 16, 369-381.
HUIDONG, M. o. 1987. Genetic expression for endosperm traits. Proceedings of the Second International Conference on Quantitative Genetics. Sinaur Associates, Massachussetts, pp. 478-487.

JINKS, J. L. 1954. The analysis of continuous variation in a diallel cross of Nicotiana rustica varieties. Genetics, 39, 767-788.

JINKS, J. L. 1955. A survey of the genetical basis of heterosis in a variety of diallel crosses. Heredity, 9, 223-238.

JINKS, J. L. 1956. The $F_{2}$ and backcross generations from a set of diallel crosses. Heredity, 10, 1-30.

JINKS, J. L. AND STEVENS, J. M. 1959. The components of variation among family means in diallel crosses. Genetics, 44, 297-308.

JONES, R. M. 1965. Analysis of variance of half diallel table. Heredity, 20, 117-121.

JULIANO, B. o. 1971. A simplified assay of milled rice amylose. Cereal Sci. Today, 16, 334-338.

KUMAR, I. AND KHUSH, G. S. 1988. Inheritance of amylose content in rice (Oryza sativa L.) Euphytica, 38, 261-269.

POONI, H. S., KUMAR, I. AND KHUSH, G. S. 1992. A comprehensive model for disomically inherited metrical traits expressed in triploid tissues. Heredity, 69, 166-174.

POONI, H. S., KUMAR, I. AND KHUSH, G. S. 1993. Genetical control of amylose content in selected crosses of indica rice. Heredity, 70, 269-280. 